\title{
Methodological Analysis about the Potential Avoidability of Motor Vehicles Colliding Against Pedestrians in Urban Areas
}

\author{
Julià Cabrerizo Sinca \\ $\mathrm{PhD}$ Student in Civil Engineering, Polytechnic University of Catalonia \\ José Magín Campos Cacheda
}

Doctor in Civil Engineering, Professor at the Polytechnic University of Catalonia

Fernando Pérez Díez

PhD Student in Civil Engineering, Polytechnic University of Catalonia

\section{SUMMARY}

The main motivation of the authors of this article is to establish a rigorous definition of the potential capacity that a motor vehicle driver has to avoid a collision against a pedestrian. Henceforth we will call this capacity avoidability.

To calculate the avoidability, it is necessary to analyze time, distance and itinerary, initial position of the pedestrian when exposed to the risk, initial speed; theoretical maximum speed developed by the vehicle and road limit speed; the driver's reaction time and the influence of the environment; and the interrelation of the initial positions of vehicle and pedestrian with respect to the transversal axis of the road.

The definition, categorized by variables, of a driver's ability to avoid run over a pedestrian in an urban area has an evident usefulness: it allows knowing the influence of the initial speed of a vehicle as an isolated variable and the importance of the road limit speed in the ability to prevent an accident. 


\section{INTRODUCTION}

\subsection{State of the issue and authors' motivations}

Over a year's time, approximately 1,240,000 people die in traffic accidents worldwide, of which 22 percent, that is to say, 272,000 deceased are pedestrians. ACTAR (2013); Europa.edu. (2013); OMS (2002); OMS. (2004); OMS (2009).

The main motivation of the authors of this article is to establish a rigorous definition of the potential capacity that a motor vehicle driver has to avoid a collision against a pedestrian. Henceforth we will call this capacity avoidability.

Once it is reliably defined which the variables and the interrelationships that determine the avoidability are, it will be feasible to develop protocols and strategies for trying to diminish the probability of being run over.

The database used as a platform for this study contains 380 cases of pedestrians that have been run over in urban areas, happened in different cities and villages of the Spanish State. The time frame includes the last ten years, and all of them have as a common characteristic that the result of the collision has been people seriously injured or death. Chisvert, M. (2000); Haddon, W. (1980); Servei Català del Trànsit (2000)

Each case, profusely documented (police statements, specialist's damages reports, medical reports of injuries, etc.), has been submitted to an exhaustive analysis and technically reconstructed, and from this work, 200 variables have been derived for each studied case.

Batista, M. (2010); Brach, R. (2005); CESVIMAP. (2006); DGT. (2011); Eubanks, J. (1994); François, D. (2011); Limpret, R. (1999) \& López Muñiz, M. (2000)

\begin{tabular}{|l|l|l|l|}
\hline & SPAIN & EUROPE & WIDEWORLD \\
\hline Traffic accidents with casualties & 83,115 & $1,077,700$ & $50,000,000$ \\
\hline Seriously injured & 10,444 & 250,000 & $15,000,000$ \\
\hline Death & 1,903 & 28,126 & $1,234,026$ \\
\hline \multicolumn{5}{|l}{} \\
\hline Run over & 10,028 & 226,317 & $12,500,000$ \\
\hline Seriously injured & 1,840 & 40,737 & $2,500,000$ \\
\hline Death & 355 & 3,937 & 272,000 \\
\hline
\end{tabular}

Table 1- Impact of traffic accident rate: territorial comparison (2012)

Own design made with data from:

\begin{tabular}{|l|}
\hline European Commission/Directorate General Energy and Transport (2014.) \\
\hline DGT (2012). Las principales cifras de Siniestralidad Vial en España. \\
\hline World Health Organization (2013) Global Status Report on Road Safety \\
\hline Extrapolation made by the authors \\
\hline
\end{tabular}




\subsection{Presentation of the Being Run Over concept under analysis}

The Dictionary defines run over as: to collide with, knock down, and often pass over people or animals generally causing them injuries.

The concept of run over which is object of analysis in this article, though in spirit similar to the aforesaid, it is more restrictive in its definition and it has the next characteristics:

The motor vehicle is the one that collides with the pedestrian.

The impact may be frontal, front-lateral and lateral, and it produces a projection of the pedestrian body in the same direction of the collision.

Also, depending on the pedestrian's body height in the moment of the colliding and the vehicle frontal part configuration, it may happen that this one passes over that one. We will call this a "running over".

The 380 analyzed cases of collisions with pedestrians that serve as basic information for this article making-up have occurred in urban areas, and they are characteristic because they have happened with speed rates significantly lower than the ones that have taken place out of the cities.

In all the cases of running over studied, the result was damages for people who had been run over. 19.7 per cent were seriously injured and 19.2 per cent resulted death.

So, the running over here analyzed occurs when a motor vehicle hits and ejects or hits and runs over a pedestrian's body. The collision scenery is an urban area and the severity of the damages is high.

\subsection{Presentation of the Avoidability Concept}

The word avoidability is not an entry in dictionaries. The more similar terms are avoid, avoidable, unavoidable and unavoidability.

Dictionaries defined these words as:

Avoid (verb): To keep out of the way of / To refrain from doing / To prevent from happening.

Avoidable (adjective): Capable of being avoided or warded off.

Unavoidable (adjective): Unable to be avoided.

Unavoidability (noun): The quality of being impossible to avoid or evade.

In the case of the word that we are coining, we understand that avoidability is the positive meaning of unavoidability and so the quality of being possible to avoid or evade, and though dictionaries do not include it, its form and its sense are perfectly understandable. The fact that "unavoidability" is included in dictionaries gives validity to our arguments: 


$$
\begin{aligned}
& \text { Unavoidable } \rightarrow \text { Unavoidability } \\
& \text { Avoidable } \rightarrow \text { Avoidability (term coined in this article) }
\end{aligned}
$$

“Cite": American Heritage ${ }^{\circledR}$ Dictionary of the English Language, Fifth Edition. Copyright $\odot 2011$

In the field of Traffic Accidents Reconstruction, avoidability is a concept full of meaning and it is used by a wide community of technical professionals: engineers, physicists, mathematicians and other professionals linked to law: judges, prosecutors and lawyers. Alvarez, F. (1996); Cabrerizo, J (2003); DGT (2010); Montoro, L. (2000); Murrieta, M.C. (2012).

Within the ambit of this study, the term avoidability defines the potential of a motor vehicle driver to elude the colliding with a pedestrian exposed to the risk. This derives from the interaction between:

-The pedestrian and motor vehicle previous relative positions and travel speeds.

-The driver's capacity of perception and reaction.

-The environmental circumstances.

To calculate the avoidability, it is necessary to analyse time, distance and itinerary, initial position of the pedestrian when exposed to the risk, initial speed; theoretical maximum speed developed by the vehicle and road limit speed; the driver's reaction time and the influence of the environment; and the interrelation of the initial positions of vehicle and pedestrian with respect to the transversal axis of the road.

\subsection{The usefulness of the definition of the Avoidability Concept}

The definition, categorized by variables, of a driver's ability to avoid run over a pedestrian in an urban area has an evident usefulness: it allows knowing the influence of the initial speed of a vehicle as an isolated variable and the importance of the road limit speed in the ability to prevent an accident.

Both vehicle initial speed and road limit speed can be changed by public policies implemented by policy makers and technical managers and so directly influencing the running over avoidability in urban areas. Bermudez, J. (2008) \& Kreamer, K. (2005); McLean A.A. (1994)

\section{VARIABLES DESCRIPTION}




\subsection{Initial Moment of Exposure to Risk}

In the running over dynamic, the moment of initial risk is generated just in the instant that the pedestrian barge into the potential trajectory of any vehicle with a preferential use of the road, and with his body takes up a part of the driveway.

We consider that this is the moment, and not before, though there were a postural, behavioural or dynamic potential demeanour that might offer previous information to the driver, in which the pedestrian exposes himself to risk.

In this study, the cases in which the vehicle barge into pedestrian's exclusive areas have been excluded since the dynamic of running over and the avoidability are subjected to different factors. Huguenin, R.D. (1988)

\subsection{Initial Moment of Risk Detection}

The initial moment of risk detection occurs when the driver perceives the pedestrian taking up space of the driveway with his body. This moment may coincide with the initial moment of the pedestrian exposure to risk, which would show that the driver had his attention completely focused in the driving and that there were no other elements (vehicles, urban furniture, etc.) that hindered his viewing of the driveway intruder. Barber, C. (1994); Egea, A. (2010); Recarte, M. A. (2003)

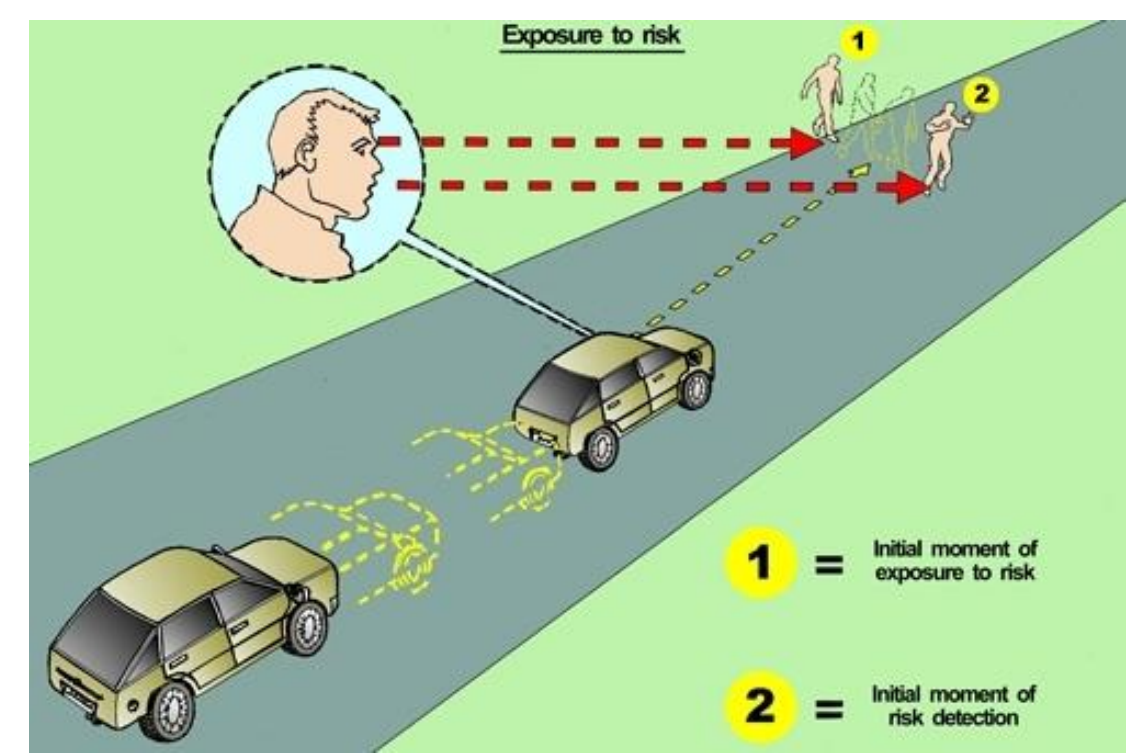

Illustration 1. Graphical representation of the Exposure Initial Moment and the Risk Detection Moment

\subsection{Initial Speed of the Vehicle}


The initial speed is the one at which the vehicle runs at the precise instant in which the driver perceives the exposure to the risk of the pedestrian when this one has barged into the way and is carrying out his projected itinerary.

\subsection{Maximum Speed of the Theoretical Avoidability}

This is the maximum driving speed in which the vehicle still has time and space enough to decelerate and stop before intercepting the pedestrian's itinerary tracing or, if not stopping, to cross it in a point that the pedestrian has already passed in his transversal movement through the road.

This speed must be compared with the real initial speed and with the road limit speed in order to determine the avoidability of running over.

\subsection{Road Limit Speed}

This is the maximum speed of driving allowed in a road section. This limitation is established following administrative criteria and therefore it is not exclusively based on the physical limitation of the road infrastructure.

The criteria to establish this speed must be based on the road own characteristics (typology, profile, location, etc.) and must be calculated by qualified specialists with the intention to guarantee the road user's safety.

The choice of a road limit speed in urban areas has a capital importance since the high transit density of pedestrians -and the relative speed differences between a motor vehicle and a pedestrian-makes that the potential conflict (coincidence of vehicle and pedestrian in a same point) always involves a high level of damages risk to the former. OCDE /CEMT (2006).

\subsection{Pedestrian's Travel Speed}

The travelling speed of a pedestrian is clearly defined by two variables: age (classified by intervals) and travelling dynamics (walking, jogging or running). There are biomechanical studies that define these two variables. Herms, B.F. (1970); Stevenson, T. (2006)

\subsection{Driver's Reaction Time}


Since the senses of a human being perceive a stimulus until he activates a reaction as a response, it starts a whole series of electric, biochemical and cognitive mechanisms that imply a dilate of time between the stimulus and the response. This is what we defined as "Reaction time". Conti, F. (2010); Lillo, J. (1995)

In the case of a motor vehicle driver in the scenery of a "running over" situation, the initial stimulus is the perception of the pedestrian barging into the driveway and exposing himself to risk. The driver's immediate reaction, if it comes to happen before of running over, would be to make a braking manoeuvre. The time of reaction between the perception of the risk and the activation of the brake pedal may be divided into three phases:

Perception: the driver perceives the potential risks

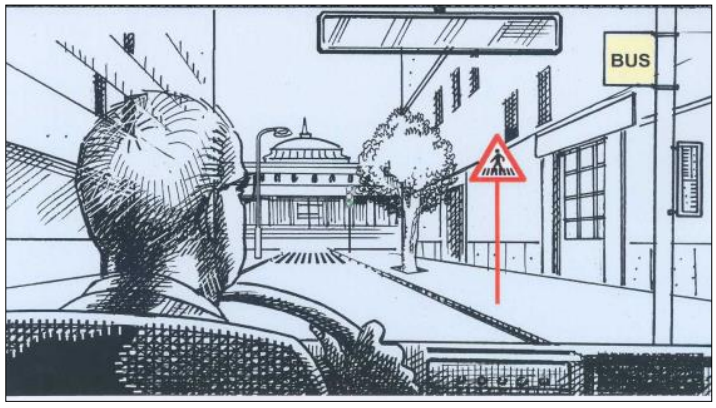

"Perception of the general environment and its potential risk"

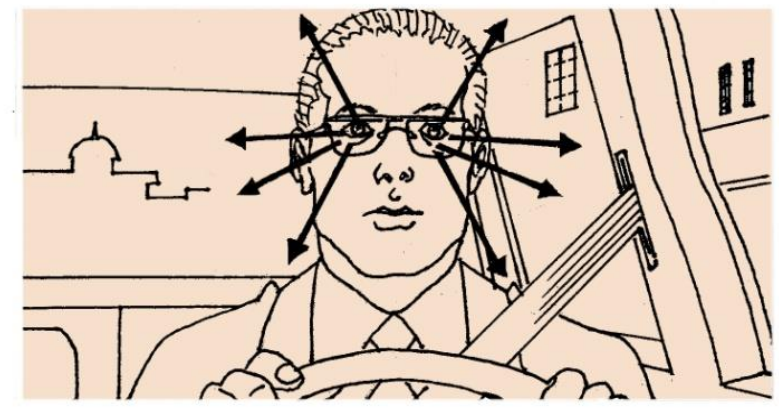

"The driver devotes himself to the driving"

Decision. Planning of a strategy to avoid or minimize the risk situation.

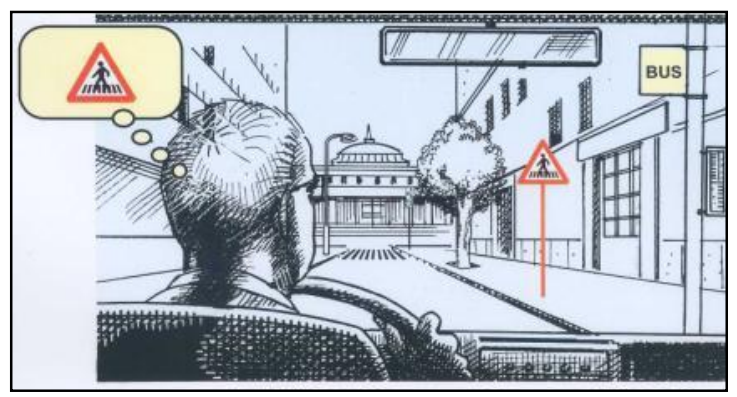

"Perception of the pedestrian crossing"

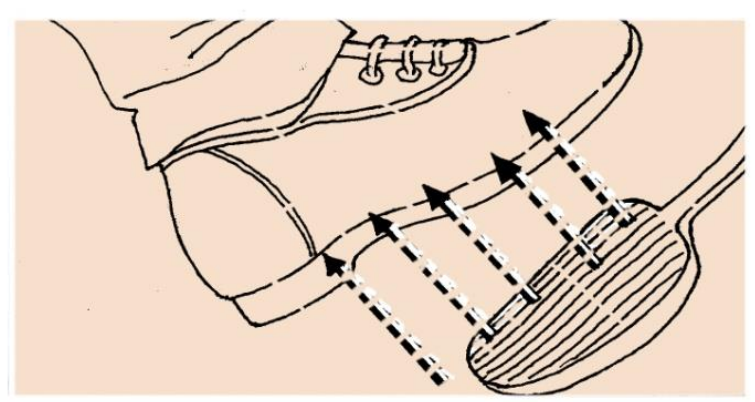

"Raising de foot from the accelerator pedal"

Action. Performing of the response action (Step on the brakes).

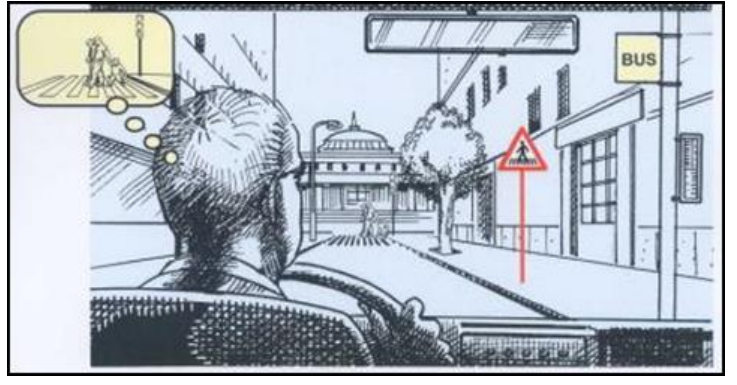

"Perception of the pedestrians crossing"

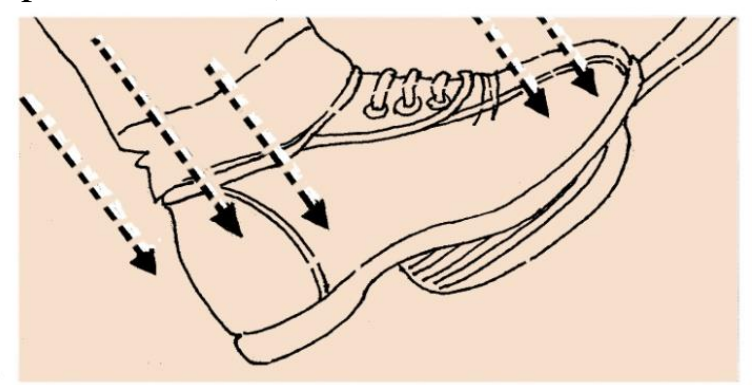

"Pushing on the brakes"

Ilustration 2. Graphical representation of the driver's reaction time.

The time of reaction varies with age, visibility and driver's level of attention.

Rivers, R.W. (2011); Servei Català de Trànsit. (2000) 


\subsection{Total Time of Exposure}

With respect to the dynamic of "running over", the risk starts in the moment in which the pedestrian barges into the driveway, and the accident takes place in the moment in which the vehicle and the passer-by collide inside the road.

So, the total time of exposure to risk has a double complementary definition:

-The time elapsed from the moment the pedestrian generated the risk situation to the moment the person's body collides with the vehicle.

-The time elapsed from the moment the pedestrian generated the risk situation to the moment in which he leaves the road without having collided with the vehicle.

The dimension of this time is very relevant when it is needed to quantify the risk borne by the pedestrian and the "avoidability" of the "running over". It is clear that the greater the time of exposure to risk, the more likely the crash. Rosem, E.S. (2011); Shinar, D. (2007); Thorson, O.P. (2002)

\subsection{The transvers position of the vehicle on the road}

The ways where the accidents happen have different profiles, widths and number of lanes. In the moment in which a pedestrian originates a risk situation in barging into the driveway, the vehicle is situated inside this one and specifically in a particular lane of it.

The transverse position of the vehicle inside the road is a variable to be valued since, depending on its interaction with the pedestrian's position and the travelling speed of each one, the trajectories of vehicle and pedestrian might coincide or not.

If the vehicle follows a straight trajectory close to the sidewalk, and the pedestrian barges into the driveway following a trajectory that goes from the right to the left, it is probabilistically more feasible that his transversal displacement moves him away from the potential point of collision. However, if the vehicle is situated in the middle of the driveway it is more feasible the two trajectories to be coincident.

\section{DIAGRAM}




\subsection{Graphical presentation of the interconnection between variables}

The aim of the next diagram is to show the avoidability logical sequence of a running over.

The first significant factor that we propose is the driver's focusing his attention on driving. This factor -though not definitive- is decisive for the potential avoidability of the running over.

Afterwards, we have exerted ourselves to define all the relevant variables that determine the initial situation of the pedestrian exposure to risk and to establish the interrelation between each other.

This diagram will prove to be helpful to select and classify all the information that derives from the research of a running over in order to determine whether this one was avoidable from the initial moment of the pedestrian's exposure to risk:

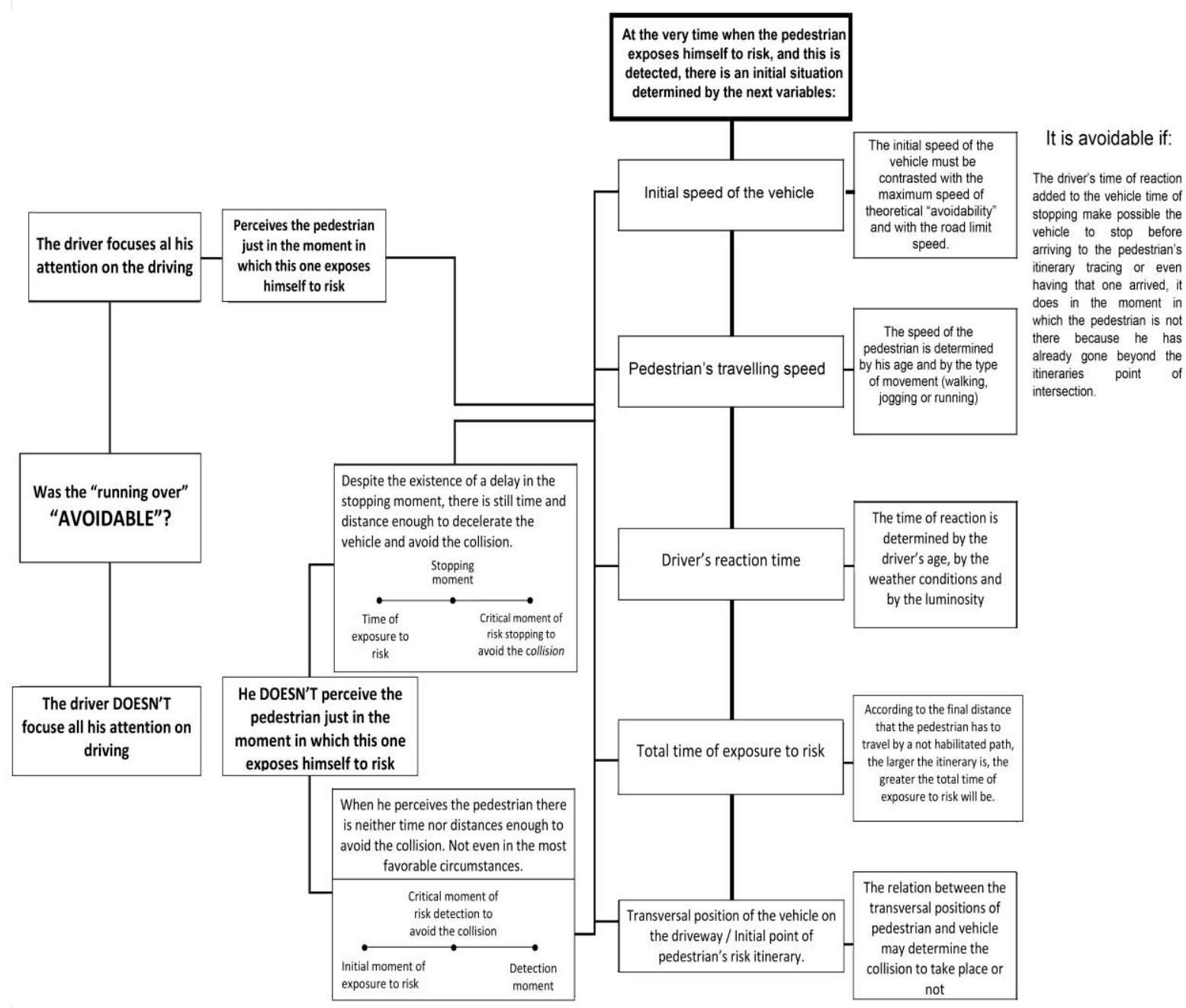

\section{ANALYSIS OF THE INTERACTION BETWEEN VARIABLES}




\subsection{Risk: Presence, Perception, Time and Distance}

There is always a risk of running over when a pedestrian goes walking out of the sidewalks or out of places exclusively meant for him, that is to say, when he may coincide with motor vehicles at the same time and in the same place. Mcpherson, A.L. (1988)

We say "always" despite the itinerary that the pedestrian follows may be habilitated by pedestrian crossings, regulated by traffic lights or conditioned by speed limits. The fact that there is a regulatory signage that establishes the road user's right of way may obviously graduate this risk but not eliminate it totally. Martin, S. (2012)

The perception of the risk by the driver depends mainly on three factors:

One, that he maintains the attention exclusively focused on the driving, observing carefully the space that he will subsequently occupy in moving whit his car and always vigilant in order to process all the information that he may capture through his vision.

Two, that the pedestrian, when exposing himself to risk, he makes it clearly without hiding his initial position nor the first sections of his itinerary, that is to say, not walking behind physical elements (dustbins, vegetation, parked vehicles, etc.) that may hinder the visibility.

Three, the existence of other conditioning factors in the road that may make difficult the driver's perception. When a crash of a motor vehicle with a pedestrian happens it is often because there is a traffic environment shared with other users of the way that produces lots of stimuli (other vehicles, pedestrians, specific signing, urban furniture, road works, etc.) that may take away the driver's attention from the presence of a pedestrian exposing himself to risk.

The risk is arranged in order of the distance and the time of approach that there is between the vehicle and the pedestrian. The greater the distance and the time of approach, the lesser the risk, since the pedestrian will be able to leave the driveway and get back to places exclusively meant for him and the vehicle driver will have more time and space to develop a preventive strategy of driving aimed to avoid to run over the pedestrian.

The approach time between the passer-by and the vehicles is determined by the travelling speed of either of them. In order to be able to reduce the "running over" cases in urban areas, the speed limits must be established taking into account the relative difference of speed between people and motor vehicles. O'Riordan K.T. (2003)

\subsection{Speed: Comparison between Initial Speed, Avoidability Maximum Speed and Road Limit Speed}

The Initial Speed at which a vehicle is running before his driver detects a potential risk must 
be contrasted with the theoretical Avoidability Maximum Speed, which is the one that would allow the vehicle to stop before coinciding with the pedestrian in any point of his itinerary. If the Initial Speed is higher than the Theoretical Avoidability Maximum Speed, the collision between the two bodies will be unavoidable, unless the pedestrian does not coincide spatially in the distance between the points the vehicle occupies while it reaches, occupies and goes past the pedestrian's risk itinerary.

\subsection{Perception Time: influence in Avoidability}

Running at the same speed and in the same environment (luminosity and weather), the running over may be avoidable or not depending on the driver's age and on the personal state in which he is.

The progressive increase of a driver's age makes too the driver's time of reaction raises inexorably, slowing thus the completion of the action-response to the stimulus that has been produced.

A young driver of eighteen years may need only half a second to elaborate an immediate response and instantly starting to implement it, while a driver of fifty six may need up to two seconds; it is to say, quadruple the reaction time in an identical situation.

The driver's psychological state and his physical condition, modified by driving fatigue, drowsiness, alcohol or drugs, increases glaringly the time of reaction (a moderate blood alcohol concentration of 0.50 grams per liter might increase half a second the time of reaction). Anderson, P. B. (2006); DGT (2008); Montoro, L. (2000); Verster, J.R. (2008)

\subsection{Avoidability: Categorical definition and variables integration}

In order to determine if a driver had the endogenous capacity and the exogenous possibility to elude the collision of his motor vehicle with a pedestrian exposed to risk, a number of conditioning variables must be taken into account:

Endogenous variables:

The driver FOCUSES/DOES NOT focuse all his attention on driving. The driver PERCEIVES the pedestrian at the initial moment of risk. The driver DOES NOT perceive the pedestrian at the initial moment of risk but there is time to avoid the collision.

The driver DOES NOT perceive the pedestrian at the initial moment of risk and there is already no time to avoid the collision.

Driver's time of reaction (age, psychological state and physical conditions).

Exogenous variables:

Initial speed of the vehicle. 
Pedestrian's travelling speed.

Total time of exposure to risk.

Vehicle transversal position on the driveway.

Starting point of the pedestrian's itinerary of risk.

Driver's time of reaction (Luminosity and weather)

Environment multi-stimulus: the rest of the users of the way, urban furniture, signing, driveway works...

The term avoidability, then, tries to define the driver's potentiality to elude the impact between a motor vehicle and a pedestrian exposed to risk. This potentiality is derived from the interaction between:

The driver's degree of concentration.

The driver's perceptive and reactive capacity.

The previous relative positions and travelling speeds of vehicle and pedestrian.

The environmental circumstances.

Avoidability is a complex concept and its definition depends on the analysis of a numerous of variables and the interrelation between them: the driver's concentration in the initial moment of the risk, his time of reaction, the environmental influence over him; time, distance, itinerary and the initial position of pedestrian's exposure to risk; the vehicle initial and theoretical maximum speeds, the road limit speed; the pedestrian's travelling speed and the interrelation of the vehicle and pedestrian's initial positions with respect to the driveway transverse axis.

\subsection{Avoidability: conversion of a Boolean variable into a continuous variable}

To concede a Boolean nature to the avoidability variable is appropriate since its condition is avoidable or not avoidable. Even so, it seems more interesting to work with a continuous rate (not discrete) about the "avoidability eluding so to give up information or to dilute it in the statistical analysis.

An accident may be not avoidable but it may be close to being avoidable, but de Boolean variable does not make this kind of discriminations, so at the moment of making a regression analysis we consider more precise to work on a unit of a continuous nature instead of a discrete one (Boolean). Operating in this manner we maintain the information about how close or how far something has been to avoidability.

Once the model has been extracted, then we can grant the status of Boolean to the variable and to embody it in the corollary. Rice, J.A (2007); Verhoeve, R.K. (2001)

We proposed the next avoidability rate: AVR (\%) 


$$
A V R=\frac{100 \times A T}{R S T_{\text {average }}}
$$

AT: Avoidability Time

RST: Risk Situation Time

If the rate is superior to $100(\mathrm{AVR}>100)$ : Unavoidable

If the rate is inferior to $100(\mathrm{AVR}<100)$ : Avoidable

Since two speeds are taken in account (vehicle real speed and road maximum speed), so we define two rates:

Avoidability Rate at vehicle speed (or real):

$$
\begin{gathered}
A V R_{\text {veh speed }}=\frac{100 \times A T_{\text {veh speed }}}{R S T_{\text {average }}} \\
A V R_{\text {veh speed }}=\frac{100 \times(F+G+0.25)}{R S T_{\text {average }}}
\end{gathered}
$$

Avoidability Rate at road maximum speed:

$$
\begin{gathered}
A V R_{\text {veh } \max }=\frac{100 \times A T_{\text {veh } \max }}{R S T_{\text {average }}} \\
A V R_{\text {veh } \max }=\frac{100 \times(F+G+0.25)}{R S T_{\text {average }}}
\end{gathered}
$$

\section{CONCLUSIONS}

The endogenous capacity that a driver -conditioned by the exogenous possibilities of a given 
environment-converges at the attempt of eluding the collision between a vehicle motor and a pedestrian exposed to risk. This is the concept that we have tried to define coining at the same time the word "avoidability" in this article.

We have also tried to describe the most significant variables (relating to avoidability) that converge at a running over accident. Some of them might be considered of little significance a priori, as for example, the interaction between the transvers initial positions of motor vehicle and pedestrian, the pedestrian's travelling speed, the total time of exposure to risk of the pedestrian, the distance between motor vehicle and pedestrian in the initial moment of the pedestrian's exposure to risk and the multi-stimulus the driver receives from the environment where the accident takes place. One of the aims is to value these variables as useful determining factors for analyzing the dynamic of running over.

The usefulness of defining avoidability and to categorize its concept by means of the variables and the interrelations that converge at an accident is multiple since it allows to know the measurable influence of any variable in isolation and thus to look for strategies that allow us to anticipate the results in order to modify the variables with the goal of getting a patron for avoiding the "running over".

Both vehicle initial speed and road limit speed can be modified by public policies and implemented by policy makers and technical managers who, therefore can influence on the avoidability of running over in urban areas.

\section{REFERENCES}


ACTAR. (2013). Consultat el 03 / 12 / 2013, a Accreditation Commission for Traffic Accident Reconstruction: www.actar.org

Álvarez, F. (1996). Seguridad vial y medicina de tráfico. Barcelona: Masson.

Anderson, P. B. (2006). Alcohol in Europe. Conclusions and Recommendations. European Comission, (p. 397-418). Brussels.

Barber, C. (1994). Psychological aspects of conventional in-car warning devices. Human Factors in Alarm Design (p. 193-205). London: Taylor \& Francis.

Batista, M. (2010). Some Methods of Estimating Uncertainty in Accident Reconstruction. University of Ljubljana, Slovenia: Faculty of Maritime Studies and Transport.

Bermúdez, J. (2008). Análisis biomecánico del atropello y su aplicación en el desarrollo de tecnologías de seguridad vehicular. Cuadernos de valoración. Vol. 7. Sociedad Española de Valoración del Daño Corporal.

Brach, R. (2005). Vehicle Accident Analysis and Reconstruction Methods. SAE International.

Cabrerizo, J. (2003). Accidents de trànsit a l'entorn laboral. Barcelona: Servei Català de Trànsit. Quaderns de trànsit.

CESVIMAP. (2006). Manual de Reconstrucción de Accidentes de Tráfico.

Chisvert, M. (2000). Calidad y representatividad de los datos de accidentes de tráfico: Revisión, estudio del caso español y desarrollo de propuestas para la mejora de los sistemas de recogida y tratamiento de la información sobre accidentalidad. València: Universitat de València. Estudi General.

Conti, F. (2010). Fisiología Médica. Mc Graw Hill.

DGT. (2008). El alcohol y la conducción. Madrid: INTRAS.

DGT. (2011). Principios de Biomecánica del Accidente de Tráfico. Temario Específico de la ESTT-OEP.

DGT. (2010). Siniestralidad Vial. Madrid: DGT, Observatorio Nacional de Seguridad Vial.

Egea, A. (2010). El comportamiento humano en conducción: factores perceptivos, cognitivos y de respuesta. Universidad de Murcia. 
Eubanks, J. (1994). Pedestrian Accident Reconstruction. Lawyers \& Judges Publishing Company.

Europa.edu. (2013). European Road Safety Day, dedicated to reducing pedestrian fatalities in urban areas. Brussels: European Commission.

François, D. (2007). Método de Searle Parte 1. Montevideo.

Haddon, W. (1980). Advances in the epidemology of injuries as a basis for public policy. Public Health Reports , 411-421.

Herms, Bruce F (1970) Pedestrian Cronwalk Study. Dan Diego Police Dept.Traffic Boreau.

Huguenin, R.D. (1988). The concept of risk and behaviour models in traffic psychology. Ergonomics, 31

Irureta, V. (2003). Accidentología vial y pericia. Tercera edición. Ediciones la Roca.

Kreamer, K. (2005). An analysis of Pedestrian-Vehicular crashes near Public Schools in the city of Baltimore, Maryland. Baltimore: Department of Civil and Environmental Engineering.

Lillo, J. (1995). Flujo óptico y conducción: características generales y velocidad percibida. Anuario de Psicología , (p. 1-14). Universidad Complutense de Madrid.

Limpret, R. (1999). Motor Vehicle Accident Reconstruction and Cause Analysis. Fifth Edition. Lexis Publishing.

López-Muniz, M. (2000). Accidentes de Tráfico. Problemática e Investigación. Centro de Estudios y Experimentación de Obras Públicas (CEDEX).

Macpherson, A. I. (1998). Children's Exposure to Traffic and Pedestrian Injuries. American Journal of Public Health, 1840-1843.

Martín, S. (2012). Estudio multiriesgo de los accidentes y lesionados por tráfico en la Comunidad Valenciana. Univestitat de València: INTRAS.

McLean, A. A. (1994). Vehicle Travel Speeds and The Incidence of Fatal Pedestrian Collisions. NHMRC Road Accident Research Unit The University of Adelaide: Federal Office of Road Safety. 
Montoro, L. (2000). Manual de seguridad vial: el factor humano. Barcelona: Ariel.

Murrieta, M. C. (2012). Investigación y Reconstrucción de Atropellos.

OCDE/CEMT. (2006). Getión de la velocidad. International Transport Forum.

OMS. (2002). Estrategia quinquenal de la OMS para le prevención de lesiones por accidentes de tráfico. Accidentes de tránsito - prevención y control. Ginebra: Catalogación por la Biblioteca de la OMS.

OMS. (2004). Informe mundial sobre prevención de los traumatismos causados por el tránsito. Washington, D.C.: Publicación Científica y Técnica No. 599.

OMS. (2009). Informe sobre la situación mundial de la seguridad vial: es hora de pasar a la acción. Ginebra.

O'Riordan, K. T. (2003). Reconstruction of real world head injury accidents resulting from falls using multibody dynamics. Science Direct, 590-600.

Recarte, M. A. (2003). Mental workload while driving: Effects on visual search, discrimination and decision making. Journal of Experimental Psychology: Learning, Memory and Cognition, (p. 119-137).

Rice, J.A. Mathematical Statistics and Data Analysis. Third Edition Thompson 2007.

Rivers, R. W. (2011). Traffic accident investigators' and reconstructionists' book of formulae and tables. Universidad Estatal de Pensilvania: Charles C. Thomas Publisher.

Rosén, E. S. (2009). Pedestrian fatality risk as a function of car impact speed. Preprint of article published in Accident Analysis and Prevention 41 , 536-542.

Servei Català de Trànsit. (2000). La reconstrucció de l'accident de trànsit. Barcelona: Quaderns de Trànsit.

Shinar, D. (2007). Traffic Safety and Human Behaviour. Bingley: Emerald Group.

Stevenson, T. (2006). Simulation of Vehicle-Pedestrian Interaction. University of Canterbury.

Thorson, O. P. (2002). Pedestrian speeds in light signal controlled crossings. Intra SL.

Verhoeve, R. K. (2001). Advances in Numerical Modelling of Crash Dummies. Amsterdam: 
ESV Conference 2001, Paper Number 152.

Verster, J. R. (2008). Drugs, Driving and traffic Safety. Berlin: Birkhauser Basel. 